\title{
PROTOTYPE PEMANTAU BUS MENGGUNAKAN GPS TRACKING GEOLOCATION BERBASIS ADUINO UNO
}

\author{
Syafnidawaty ${ }^{1}$, Fredy Susanto ${ }^{2}$, Panji Gumilar ${ }^{3}$ \\ ${ }^{1}$ Jurusan Sistem Informasi, STMIK Raharja Tangerang \\ 2,3Jurusan Sistem Komputer, STMIK Raharja Tangerang \\ 1,2,3 Jl. Jend Sudirman No.40 Cikokol Tangerang \\ Email: 1'syafnidawati@raharja.info, ${ }^{2}$ fredy@ raharja.info, ${ }^{3}$ panji@ raharja.info
}

\begin{abstract}
Abstrak
Teknologi sistem pelacakan (tracking) realtime telah dimungkinkan dengan menggunakan mikrokontroler seperti arduino uno dan module GPS. Tulisan ini mengajukan mekanisme pelacakan kendaraan pada sebuah rental bus dengan GPS Tracker untuk membuat suatu sistem informasi monitoring kendaraan secara realtime. Beberapa komponen seperti Arduino Uno, SIM908 Modul, antena, dan baterai dirangkai sedemikian rupa untuk kemudian memproses data posisi kendaraan dan mengirimnya dengan menggunakan request HTTP ke web server melalui paket data/internet. Sebuah halaman web dirancang sebagai output berupa peta digital yang dapat diakses melalui web browser. Rekayasa dari teknologi tersebut dapat menghasilkan sistem pemantauan obyek bergerak yang memang sangat perlu diketahui keberadaan dan pergerakannya untuk membantu mencapai kinerja perusahaan yang optimal.
\end{abstract}

Kata kunci: GPS, GSM, Arduino, Mikrokontroler.

\section{PENDAHULUAN}

Kemajuan teknlogi GPS (Global Positioning System) yang semakin canggih telah melahirkan berbagai teknologi yang dikembangkan dengan teknologi GPS, salah satunya yaitu GPS Tracker. GPS Tracker adalah sebuah alat untuk memantau atau melacak dan penentu lokasi sebuah kendaraan menggunakan satelit GPS secara akurat dalam bentuk titik kordinat yang dapat kita amati secara realtime melalui peta digital. Hal ini dapat membantu mengurangi penggunaan biaya telepon selular dalam mengetahui posisi kendaraan, yang mana biasanya dilakukan dengan cara menghubungi kondektur/sopir secara langsung, sehingga bisa memakan biaya yang lebih mahal[1].

Fenomena kebutuhan perusahaan maupun instansi untuk penentuan posisi terhadap objek bergerak semakin meningkat. Banyak kasus dalam perusahaan taksi, distribusi barang, transportasi bus, penyalahgunaan pemakaian mobil dinas dan perusahaan jasa pengiriman barang, jasa pengiriman bbm, jasa angkutan barang pada perusahaan jasa yang membutuhkan mekanisme monitoring dalam penentuan posisi. Untuk kasus ini penulis memilih perusahaan jasa trasnportasi armada bus PT. Karuna Berkat Abadi di daerah Kabupaten Tangerang sebagai studi kasus[4].

Sampai saat ini GPS merupakan alat penentuan posisi yang paling populer di dunia tanpa dikenakan biaya pemakaian. Untuk dapatmengetahui posisi seseorang maka diperlukan alat yang diberi nama GPS reciever yang berfungsi untuk menerima sinyal dari satelit GPS. Teknologi satelit yang memungkin melakukan komunikasi di mana saja, kapan saja dan oleh siapa saja. Teknologi telekomunikasi bergerak (mobile technology) juga mengalami perkembangan yang sangat cepat dimulai dengan layanan yang kita kenal $1 \mathrm{G}$ sampai dengan $4 \mathrm{G}$ dan bahkan 5G[4].

Dalam perananya sebagai pemantau atau pelacak dan penentu lokasi, GPS saat ini bisa kita implementasikan kedalam konsep IoT. Dimana dapat dikembangkan lagi dengan membuat sebuah sistem halaman web maupun mobile sehingga bisa diepantau secara realtime. Dengan menggunakan module GPS, dan module GPRS/GSM, serta Arduino Uno sebagai mikrokontroler, kemudian menggunakan PHP dan JavaScript sebagai teknologi untuk merancang halaman web, maka dapat membuat sebuah GPS Tracker dengan konsep IoT. 


\section{Arduino Uno}

Arduino Uno adalah sebuah board mikrokontroller yang didasarkan pada ATMega328 (datasheet).

\begin{tabular}{|l|l|}
\hline Mikrokontroller & ATmega 328 \\
\hline Tegangan Pengoperasian & $5 \mathrm{~V}$ \\
\hline Tegangan Input yang disarankan & $7-12 \mathrm{~V}$ \\
\hline Batas Tegangan Input & $6-20 \mathrm{~V}$ \\
\hline Jumlah pin I/O digital & $\begin{array}{l}14 \text { pin digital (6 diantaranya } \\
\text { menyediakan keluaran PWM) }\end{array}$ \\
\hline Jumlah pin input Analog & 6 pin \\
\hline Arus DC tiap pin I/O & $40 \mathrm{~mA}$ \\
\hline Arus DC untuk pin 3,3 V & $50 \mathrm{~mA}$ \\
\hline Memori Flash & $\begin{array}{l}32 \mathrm{~KB} \text { (ATmega 328) sekitar 0,5 KB } \\
\text { digunakan oleh bootloader }\end{array}$ \\
\hline SRAM & $2 \mathrm{~KB}$ (ATmega 328) \\
\hline EPROM & $1 \mathrm{~KB}$ (ATmega 328) \\
\hline Clock Speed & $16 \mathrm{MHz}$ \\
\hline
\end{tabular}

Gambar 1. Keterangan Arduino Uno

\section{GPS \& GSM Shield (SIM908)}

SIM908 adalah anggota pertama dari keluarga baru modul berbasis ARM926EJ-S yang menggandakan frekuensi kinerja inti dibandingkan dengan modul berbasis ARM7 biasa.

Tabel 1. Karakteristik Modul SIM908

\begin{tabular}{|l|l|}
\hline \multicolumn{2}{|c|}{ GPS } \\
\hline Sensitivitas GPS & $143-160 \mathrm{dBm}$ \\
\hline $\begin{array}{l}\text { kecepatan } \\
\text { deteksi }\end{array}$ & 1 detik \\
\hline Akurasi & $<2,5 \mathrm{~m} \mathrm{CEP}$ \\
\hline Konsumsi arus & $76-77 \mathrm{~mA}$ \\
\hline Penerima Sinyal & GPS L1 C/A code \\
\hline \multicolumn{2}{|c|}{ GSM/GPRS } \\
\hline Quad-band & $\begin{array}{l}850 / 900 / 1800 / 1900 \\
\text { MHz }\end{array}$ \\
\hline $\begin{array}{l}\text { Kecepatan } \\
\text { unduh }\end{array}$ & hingga 85,6 KBps \\
\hline Channel control & Mendukung PBCCH \\
\hline TCP/IP Stack & Terintegrasi \\
\hline
\end{tabular}

\section{HASIL DAN PEMBAHASAN}

Global Positioning System (GPS) adalah teknologi yang digunakan untuk menentukan posisi di permukaan bumi menggunakan satelit. Teknologi ini menggunakan 24 satelit yang mengirimkan sinyal gelombang mikro ke Bumi. Sinyal ini digunakan untuk menentukan letak, kecepatan, arah, dan waktu[2].

GPS Tracker merupakan teknologi yang berfungsi untuk mengetahui posisi kendaraan secara realtime[3]. Dengan menggunakan modul SIM908 yang didalamnya terdapat teknologi GSM, juga berkemampuan GPRS untuk transmisi data melalui mobile internet network dan dilengkapi dengan fungsi real GPS (L1 C/A Code) dengan akurasi hingga 2,5 meter. Kedua fitur ini sangat cocok untuk diaplikasikan pada perangkat bergerak, misalnya sebagai penjejak kendaraan (GPS tracker).

\section{A. Perancangan Prototype}


Dalam perancangan disusun menyerupai alat sistem akses pada umumnya. Alat ini dilengkapi dengan komponen seperti: Arduino Uno, GPS dan GPRS/GSM Shield (SIM908 Module), eksternal GPS antena, eksternal GSM antena, 9V Battery, dan 2300m/Ah Battery, serta web browser dan Personal PC untuk mendukung kinerja alat tersebut, berikut diagram blok beserta alur kerjanya :

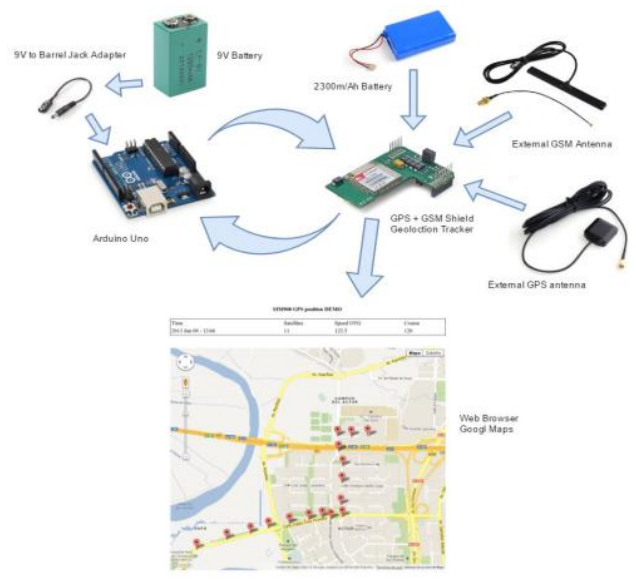

Gambar 2. Diagrm Blok

\section{Literature Review}

Literature Review ini adalah sebagai acuan apakah penelitian yang dibuat ada unsur plagiat dan apakah ada korelasi dengan penelitian penelitian yang lain. Karena dalam penelitian yang dibuat ini adalah pemanfaatn aplikasi google map dengan gps tracking yang realtime.

1. Penelitian yang dibuat oleh Chintya nermelitika dkk Universitas Telkom, eproceeding of Applied Science Vol.1No.3 desember 2015. Dengan Judul RANCANG BANGUN PELACAK BUS UNTUK SMART CITY, tidak menggunakan aplikasi geotracking pada google. Hanya menggunakan GPS yang terhubung dengan arduino.

2. Penelitian yang dibuat olehFatmah Riszkidiniah dkk, Universitas Halu Oleo Kendari, Semantik vol.2No.2 Des 2016 dengan judul PERANCANGAN DAN IMPLEMENTASI PROTOTYPE SISTEM GPS (GLOBAL POSITIONING SYSTEM) DAN SMS GATEWAY PADA PENCARIAN KENDARAAN BERMOTOR BERBASIS ARDUINO UNO, menerangkan penelitian dengan sms gateway tidak menggunakan aplikasi Geo tracking. Masih banyak lagi penelitian lainnya, yang hanya menggunakan gps dan sms gateway yang terhubung dengan arduino. Disini penulis menggabungkan dengan apliakasi geotracking google dengan gps yang terhubung dengan arduino.

Rangkaian disusun sebagai simulasi dari alat yang dirancang sehingga pemetaan pada saat perakitan alat menjadi lebih terstruktur dan sistematis.



Gambar 3. Rankaian Skematik 
Setelah proses perancangan alat berdasarkan rangkaian skematik berhasil disusun, maka proses pemograman sudah bisa dilakukan.

Urutan proses pada alat GPS Tracking ini dimulai dengan menghubungkanya dengan internet yang kemudian modul GPS akan menerima sinyal dari satelit dan mendapatkan data posisi koordinat. Tracking berjalan, data koordinat dikirim ke web server lalu ditampilkan pada halaman browser.

Tabel 2. Tabel Kelemahan dari Sistem

\begin{tabular}{|c|l|c|}
\hline No & $\begin{array}{l}\text { Kelemahan sistem ( kondisi dimana } \\
\text { sistem tidak berjalan / berfungsi dengan } \\
\text { baik ) }\end{array}$ & $\begin{array}{l}\text { Presentase } \\
\text { keberhasila } \\
\text { n }\end{array}$ \\
\hline 1 & $\begin{array}{l}\text { Tidak tersedianya sinyal operator selular } \\
\text { GSM }\end{array}$ & 0 \\
\hline 2 & $\begin{array}{l}\text { Terjadi gangguan sinyal operator selular } \\
\text { GSM ( sinyal lemah / tidak stabil ) }\end{array}$ & $30-50$ \\
\hline 3 & $\begin{array}{l}\text { Terhalang oleh bangunan yang tebal atau } \\
\text { pepohonan lebat }\end{array}$ & $20-40$ \\
\hline 4 & $\begin{array}{l}\text { Lonjakan sumber listrik yang berlebihan } \\
\text { terhadap alat }\end{array}$ & $10-15$ \\
\hline 5 & Tidak ada sumber listrik yang memadai & 0 \\
\hline 6 & Cuaca buruk & $45-55$ \\
\hline
\end{tabular}

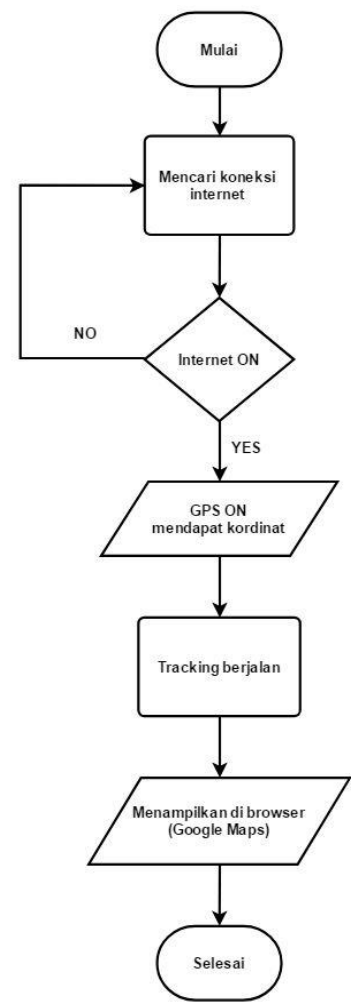

Gambar 4. Flow Chart 
Sedangkan Javascrip untuk pemograman disisi client. Javascript menginialisasi Google Maps API dan menyimpan variabel berisi koordinat posisi kendaran..
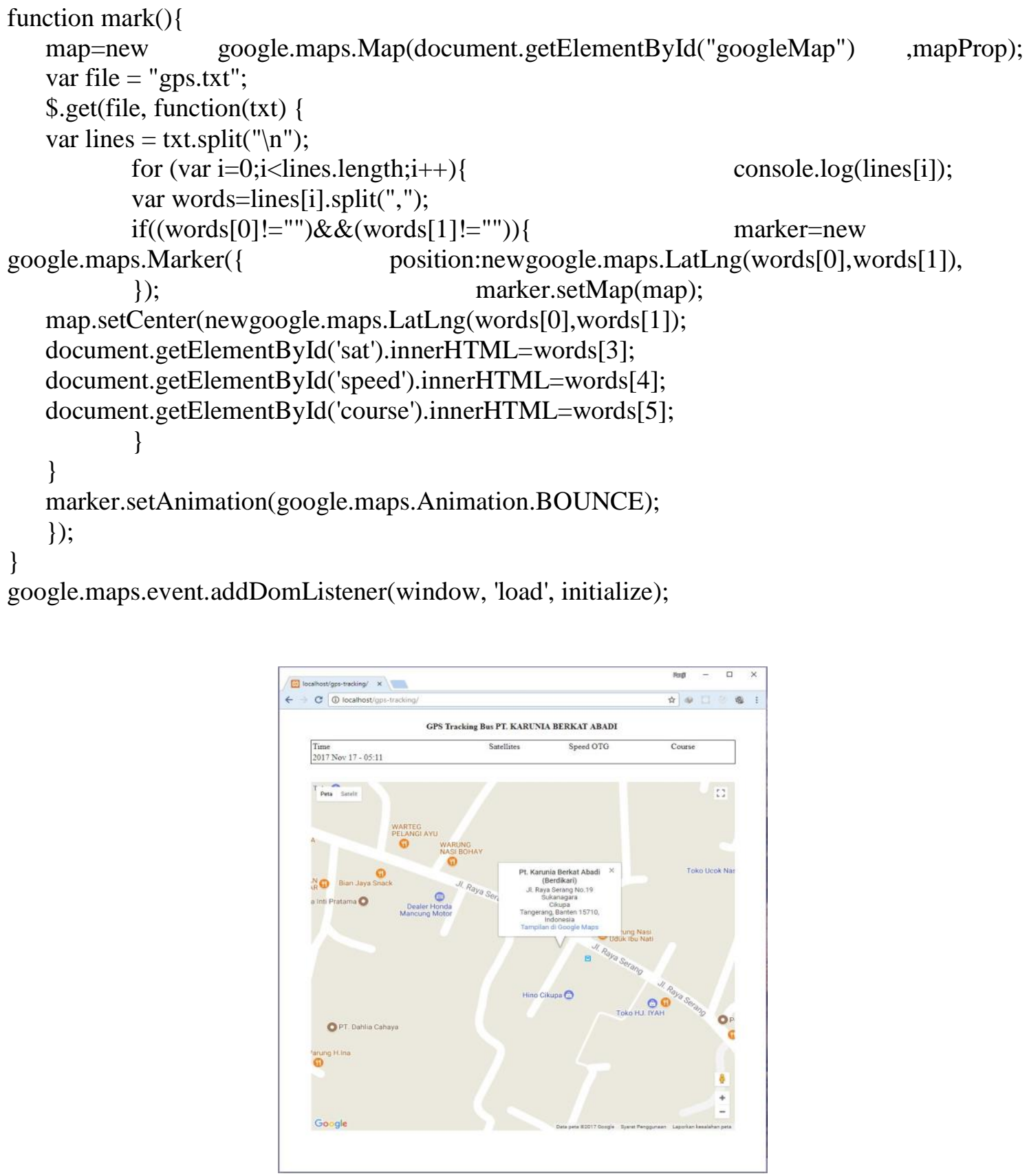

Gambar 5. Tampilan GPS Tracking

Kemampuan GPS Tracker ini dapat menghasilkan titik-titik perjalanan pada Google Maps secara akurat (akurasi hingga 2,5 meter ) sesuai dengan rute yang dituju, dan tidak akan meleset terkecuali jika terjadi hambatan. Hambatan tersebut dapat terjadi dalam beberapa karakteristik seperti tidak tersedianya sinyal operator selular (GSM), cuaca buruk, terhalang oleh bangunan semisal terowongan dan lain-lain. 


\section{KESIMPULAN}

Berdasarkan analisa yang telah diuraikan pada pembahsan sebelumnya, maka dapat diambil kesimpulan antara lain :

1. Membuat sistem pemantauan / monitoring location tracker kendaraan bus melalui peta digital (Google Maps) berbasis web.

2. Menghubungkan sistem pemantauan dengan web dari GPS yang diproses oleh modul SIM908 untuk mendapatkan data koordinat dan mengirimka data tersebut melalui koneksi GSM (internet) kepada script PHP yang ada pada web server.

3. Dengan board mikrokontroler ATMega328 (Arduino Uno) sangat dimungkinkan untuk membuat sebuah alat GPS Tracking yang dikomunikasikan dengan modul SIM908 sebagai GPS penerima sinyal satelit dan GSM/GPRS sebagai koneksi data/internet. Kemudian membuat sebuah sistem pemantauan/monitoring location tracker kendaraan bus melalui peta digital (Google Maps) berbasis web.

\section{DAFTAR PUSTAKA}

[1] Ahmad Roihan, M Sri Bintang Prasetyo \& Annas Rifa'i, "Monitoring Location Tracker Untuk Kendaraan Berbasis Raspberry Pi”, Journal Cerita Vol 3 No 2, Agustus 2017. hal 148-161

[2] I Made Oka, I Gede Agus \& Linawati, "Penerapan Teknologi GPS Tracker Untuk Identifikasi Kondisi Traffik Jalan Raya”. Jurnal Teknologi Elektro Vol 14, NO 1. Juni 2015.

[3] S. Tao, V. Manolopoulus, S. Rodeiguez dan A, Rusu, "Real-Time Urban Traffic State Estimation with A-GPS Mobile Phones as Probes", Journal of Transportation Technologies, Vol. 2, 2012, hal 22-31

[4]Hanafi, "Aplikasi Pemantauan Keberadaan Lokasi dan Kecepatan Pada Kendaraan Dengan Menggunakan Teknologi Mobile Data dan Gps Dengan Digitalisasi Peta", Jurnal Teknologi, Vol 8 Nomor 2, Desember 2015, 143-150

[5]Evy Nurmiati, "Analisis dan Perancangan Web Server pada Handphone", Studia Informatika: Jurnal Sistem Informasi, 5(2), 2012, 1-17

[6] Abdul Kadir, "Buku Pintar Pemograman Arduino". Desember 2014. hal 17 